\title{
Network Properties of Ureasil-Based Polymer Matrixes for Construction of Amperometric Biosensors as Probed by PALS and Swelling Experiments
}

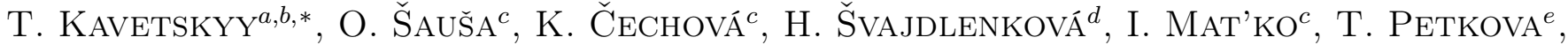

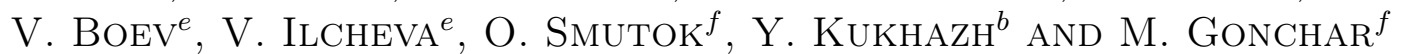 \\ ${ }^{a}$ The John Paul II Catholic University of Lublin, Al. Racławickie 14, 20-950 Lublin, Poland \\ ${ }^{b}$ Drohobych Ivan Franko State Pedagogical University, I. Franko Str. 24, 82100 Drohobych, Ukraine \\ ${ }^{c}$ Institute of Physics, Slovak Academy of Sciences, Dúbravská cesta 9, 84511 Bratislava, Slovak Republic \\ ${ }^{d}$ Polymer Institute, Slovak Academy of Sciences, Dúbravská cesta 9, 84541 Bratislava, Slovak Republic \\ ${ }^{e}$ Institute of Electrochemistry and Energy Systems, Bulgarian Academy of Sciences, \\ Acad. G. Bonchev Str. Bl. 10, 1113 Sofia, Bulgaria \\ ${ }^{f}$ Institute of Cell Biology, National Academy of Sciences of Ukraine, Drahomanov Str. 14/16, 79005 Lviv, Ukraine
}

\begin{abstract}
Network properties of ureasil-based polymer matrixes suitable for construction of amperometric biosensors were probed by positron annihilation lifetime spectroscopy and swelling experiments. Temperature dependences of the ortho-positronium (o-Ps) lifetimes and their relative intensities were measured in a temperature range of $15-$ $350 \mathrm{~K}$. Glass transition temperatures and expansion coefficients of microscopical free-volume for the investigated polymers were determined. Differences in network behavior for the aged samples and the effect of chalcogenide $\left(\mathrm{As}_{2} \mathrm{~S}_{3}\right)$ particles on the free volume of ureasil network were observed. Swelling experiments using ethyl alcohol showed that the structure of the aged sample network had less swelling ability for the pure ureasil as well as composite. This suggests that the one of factors influencing swelling is the change of the basic ureasil network due to ageing. It is supposed that the network properties obtained by positron annihilation lifetime spectroscopy and swelling experiments could be very helpful to understand better the bio-functionality of the constructed biosensor based on the ureasil-chalcogenide glass composite.
\end{abstract}

DOI: 10.12693/APhysPolA.132.1515

PACS/topics: 81.05.Lg, 81.07.Pr, 78.70.Bj, 61.25.hp

\section{Introduction}

Recently, innovative amperometric biosensors for monitoring the level of wastewater pollution have been constructed [1] on the surface of the gold planar electrodes C220AT "DropSens" by using the organic-inorganic ureasil-based composites as host polymer matrixes and immobilized commercial laccase from Trametes versicolor. In fact, urea-silicates or ureasils are well-known as representatives of organic-inorganic hybrid polymer materials successfully examined as dispersion media for luminescent $\mathrm{Eu}^{3+}$ salts [2], ion conducting $\mathrm{Li}^{+}$salts [3], organic dyes [4], semiconductor and metal nanoparticles [5-8], and, for the first time, the ureasil-based composites were tested for immobilization of laccase and construction of biosensors [1]. It has been found that the biosensor based on the ureasil-chalcogenide glass composite was characterized by very high sensitivity to be 38.3 times higher in compare with pure ureasil. On the other hand, application of the ureasil-chalcogenide glass composite with incorporated silver nanoparticles synthesized by high-dose $30 \mathrm{keV} \mathrm{Ag}^{+}$ion implantation results

*corresponding author; e-mail: kavetskyy@yahoo.com in decrease of the biosensor sensitivity up to 2390 times. Therefore, knowing the properties of the microstructure of such materials is important in terms of optimizing the regulated properties of the biosensors.

The present work is aimed to study the free-volume and swelling properties of various samples of pure ureasil and ureasil-chalcogenide glass composite by means of positron annihilation lifetime spectroscopy (PALS) and swelling experiments.

\section{Experimental}

\subsection{Sample preparation}

The synthesis of the pure ureasil matrix (K0) was performed as follows: (i) O,O'-bis(2-aminopropyl)polypropylene, glycol-block-polyethylene glycolblock-polypropylene, glycol-500 (Jeffamine ED600) were dried under vacuum for $30 \mathrm{~min}$; (ii) 3-isocyanatepropyltriethoxysilane (ICPTES), tetraethoxysilane (TEOS, 98\%) and $n$-butyl amine were used as received; (iii) Jeffamine and ICPTES were mixed in stoichiometric ratio 1:2 in order to obtain a liquid ureasilicate monomer; (iv) Thereupon, TEOS (1.12 mmol) and $n$-butylamine were added to the mixture, which was kept under stirring for more than $20 \mathrm{~min}$; (v) the mixture was transferred into a plastic Petri dish and 
jellified under appropriate conditions; (vi) the obtained gels were heated in a vacuum furnace at $60^{\circ} \mathrm{C}$ at ambient conditions; (vii) a non-rigid, homogeneous and highly transparent xerogel in form of a disk with a diameter of $40 \mathrm{~mm}$ and a thickness of $0.25 \mathrm{~mm}$ was obtained within 1 day.

The synthesis of the ureasil-chalcogenide glass $\mathrm{As}_{2} \mathrm{~S}_{3}$ composite matrix (K4) was performed as follows: (i) the chalcogenide glass $\mathrm{As}_{2} \mathrm{~S}_{3}$ ingots were synthesized by melt quenching method from $\mathrm{As}(5 \mathrm{~N})$ and $\mathrm{S}(5 \mathrm{~N})$ in sealed quartz ampoules at $650{ }^{\circ} \mathrm{C}$; (ii) the melt was quenched to room temperature, and the obtained glassy samples were finely grounded in powder form and dissolved in organic solvent ( $3 \mathrm{ml}$ of $n$-butylamine) to the $0.4 \mathrm{M}$ concentration; (iii) the $\mathrm{As}_{2} \mathrm{~S}_{3}+$ ureasil composite was obtained by mixing of the ureasilicate monomer with the solution of chalcogenide clusters. The stiff gel was obtained as described.

The images of investigated samples used for the research are shown in Fig. 1.

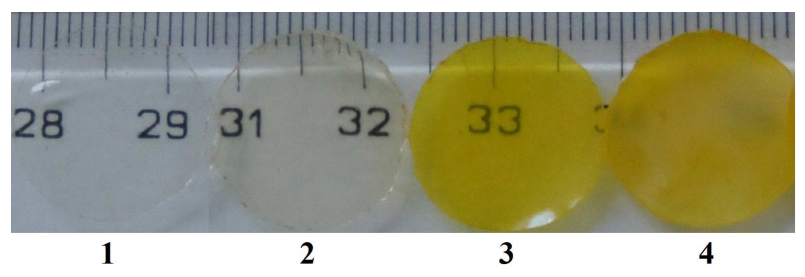

Fig. 1. Images of the investigated polymers used for the research: 1 - ureasil fresh $(2$ months after preparation): K0-fresh, 2 - ureasil aged (1 year after preparation): K0-aged, $3-\mathrm{As}_{2} \mathrm{~S}_{3}+$ ureasil fresh (2 months after preparation): K4-fresh, $4-\mathrm{As}_{2} \mathrm{~S}_{3}+$ ureasil aged (1 year after preparation): K4-aged.

\subsection{PALS experiment}

The positron annihilation lifetime spectra were taken using plastic scintillators coupled to photomultiplier tubes as detectors with the ${ }^{22} \mathrm{Na}$ positron source, deposited on a pure Kapton foil, and placed between two sandwiched samples. This source-sample assembly was covered by a special tube and placed between two detectors to acquire lifetime spectra in a vacuum at different temperatures. The time resolution (FWHM) of spectrometer was about 320 ps, measured by defect free Al sample. Analysis of lifetime spectra was carried out using the free of charge LT program with source correction of $21.8 \%$. Three component fitting procedure for PALS data treatment was applied, that gave the best fit, and long-lived lifetime component $\tau_{3}$ and its intensity $I_{3}$, ascribing to the ortho-positronium (o-Ps) pick-off annihilation in free-volume holes in accordance with the conventional interpretation [9], were finally taken into account for analysis. The low-temperature measurements were performed in the range of 15-350 K using helium cryostat (Closed Cycle Refrigerator, Janis Research Company, Inc., USA) and vacuum equipment (Pfeiffer Vac- uum, HiCUBE, Germany). The accuracy for the each selected temperature was $\pm 1 \mathrm{~K}$ and vacuum in the system was automatically controlled. The samples were measured in the cycles of "cooling-heating" with step of $20 \mathrm{~K}$ and elapsed time of $3-5 \mathrm{~h}$ per point.

\subsection{Swelling experiment}

The investigated samples were swollen in anhydrous ethyl alcohol (EtOH) during 8 days at $301 \mathrm{~K}$. One was weighed the initial weight of samples $\left(m_{0}\right)$ and then the samples after $24 \mathrm{~h}$ during 8 days. The equilibrium was achieved after 6-7 days, and on the 8th day the weight was not changed. So we have the maximum saturated weight $\left(m_{\text {swollen }}\right)$. After that the samples at room temperature were dried at $333 \mathrm{~K}$ in argon atmosphere by using thermogravimetric analysis (TGA) method where the weight of dry sample $\left(m_{\text {dry }}\right)$ was obtained as the minimum saturated mass. The percent equilibrium mass swelling $(S)$ was estimated from the equation

$$
S=\left[\frac{m_{\text {swollen }}-m_{\text {dry }}}{m_{\text {dry }}}\right] \times 100 \% .
$$

The molecular weight between two crosslink points, $M_{c}$, was estimated based on the Flory-Rehner equation $[10,11]$ :

$$
v=\frac{1}{M_{c}}=-\left[\frac{\left(V_{r}+\chi V_{r}^{2}+\ln \left(1-V_{r}\right)\right)}{\rho_{p} V_{0}\left(V_{r}^{1 / 3}-V_{r} / 2\right)}\right],
$$

where $\nu$ is the crosslinking density, $\rho_{p}$ is the bulk density of the polymeric sample, and $V_{r}$ is the volume fraction of the polymer in the swollen state given by equations

$$
\begin{aligned}
& V_{r}=1 /(1+Q), \\
& Q=\left[\frac{\left(m_{\text {swollen }}-m_{0}\right) \rho_{p}}{m_{0} \rho_{\text {liquid }}}\right],
\end{aligned}
$$

where $\rho_{\text {liquid }}$ is the density of the liquid and $V$ is the molar volume of the liquid. For EtOH $V$ is $57.62 \mathrm{~cm}^{3} / \mathrm{mol}$. The parameter $\chi$ is the Flory-Huggins interaction parameter between the polymer and the liquid. The values of $\chi$ for polymer-solvent interaction were calculated via the cohesive energy of atomic groups.

The density of the investigated polymeric samples was estimated based on the gravimetric method (Archimedean principle). The samples were immersed into EtOH at $301 \mathrm{~K}$. The bulk density of individual samples was calculated by using the following equation:

$$
\rho=\rho_{\mathrm{EtOH}}\left[\frac{m_{0}}{m_{0}-m_{1}+m_{\text {wire }}}\right],
$$

where $\rho_{\mathrm{EtOH}}$ is the density of ethanol at the temperature of $301 \mathrm{~K}, m_{\text {wire }}$ is the weight of the wire in $\mathrm{EtOH}$ and the values of $m_{0}$ and $m_{1}$ are the sample weights on air and after immersion into EtOH.

\section{Results and discussion}

Figure 2 shows the $o$-Ps lifetimes and their relative intensities for the investigated samples as a function of temperature in the range of $15-350 \mathrm{~K}$. The temperature 
where the free volume (o-Ps lifetime) changes slope is assigned as a glass transition temperature $T_{g 1}$.

The determined values of free-volume $\left(V_{h}\left(T_{g 1}\right)=\right.$ $\left.4 \pi R^{3} / 3\right)$ in the glass transition temperature $\left(T_{g 1}\right)$ and thermal expansion coefficient $\left(\alpha_{f v 1}=\right.$ $\left.\left(1 / V_{h}\left(T_{g 1}\right)\right)\left(\Delta V_{h} / \Delta T\right)[9]\right)$ of microscopical free-volume are gathered in Table I. The lower temperature at which the slope of the $V_{h}(T)$ also changes in some cases is designated as $T_{g 2}$.
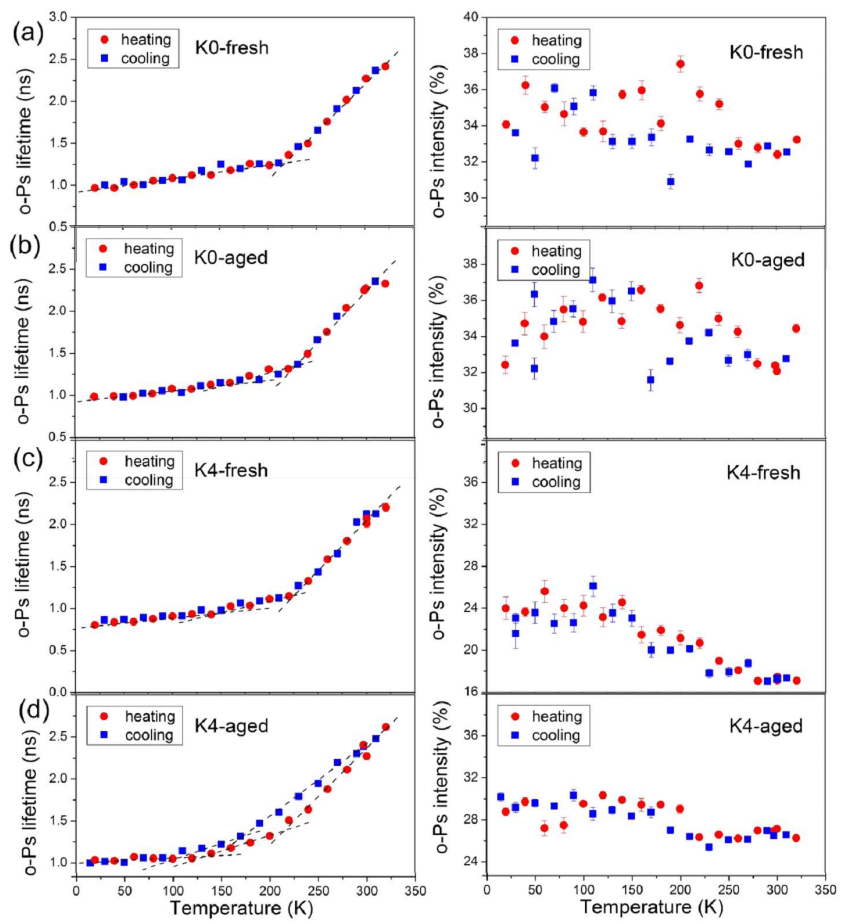

Fig. 2. $o$-Ps lifetime $\tau_{3}$ (left) and intensity $I_{3}$ (right) versus temperature for (a) K0-fresh, (b) K0-aged, (c) K4-fresh, and (d) K4-aged polymers. The samples are marked as shown in Fig. 1. The error bars for o-Ps lifetime data are within the size of the symbol. The dashed lines are drawn as a guide for the eye.

TABLE I

Free-volume $V_{h 1}$ at glass transition temperature $T_{g 1}$; lower temperature at which $V_{h}(T)$ changes the slope $T_{g 2}$; thermal expansion coefficient $\alpha_{f v 1}$ of the microscopical free-volume near $T_{g 1}$ for the investigated polymers. The samples are marked as shown in Fig. 1.

\begin{tabular}{c|c|c|c|c|c}
\hline \hline Sample & $V_{h 1}\left[\mathrm{~nm}^{3}\right]$ & $T_{g 1}[\mathrm{~K}]$ & $T_{g 2}[\mathrm{~K}]$ & \multicolumn{2}{|c}{$\alpha_{f v 1}\left[10^{-4} / \mathrm{K}\right]$} \\
\cline { 4 - 6 } & & & & $T<T_{g 1}$ & $T>T_{g 1}$ \\
\hline K0-fresh (c\&h) & $0.123 \pm 0.002$ & $216 \pm 13$ & - & $25 \pm 3$ & $286 \pm 21$ \\
\hline K0-aged (c\&h) & $0.123 \pm 0.003$ & $230 \pm 19$ & $166 \pm 89$ & $53 \pm 22$ & $273 \pm 99$ \\
\hline K4-fresh (c\&h) & $0.104 \pm 0.001$ & $227 \pm 18$ & $126 \pm 38$ & $48 \pm 1$ & $344 \pm 63$ \\
\hline K4-aged (c) & $0.134 \pm 0.001$ & $178 \pm 19$ & $88 \pm 58$ & $46 \pm 17$ & $206 \pm 56$ \\
\hline K4-aged (h) & $0.123 \pm 0.004$ & $228 \pm 38$ & $130 \pm 38$ & $56 \pm 22$ & $237 \pm 84$
\end{tabular}

Following Fig. 2 and Table I, differences in network behavior for the aged samples and the effect of chalcogenide $\left(\mathrm{As}_{2} \mathrm{~S}_{3}\right)$ particles on the free volume of ureasil network are clearly observed. Further research should be focused to resolve the nature of double $T_{g}$ values in the aged ureasil and $\mathrm{As}_{2} \mathrm{~S}_{3}+$ ureasil composites.

Figure 3 shows the results of swelling experiment for the investigated samples. The numerical parameters such as the bulk density of the polymeric sample $\rho_{p}$, and the molecular weight between two crosslink points, $M_{c}$ are presented in Table II. The higher $M_{c}$ value, the lower crosslinking density and the higher swellability. Thus, swelling experiments using EtOH showed that the structure of the aged sample network had less swelling ability for the pure ureasil as well as composite. This suggests that the one of factors influencing swelling is the change of the basic ureasil network due to ageing.

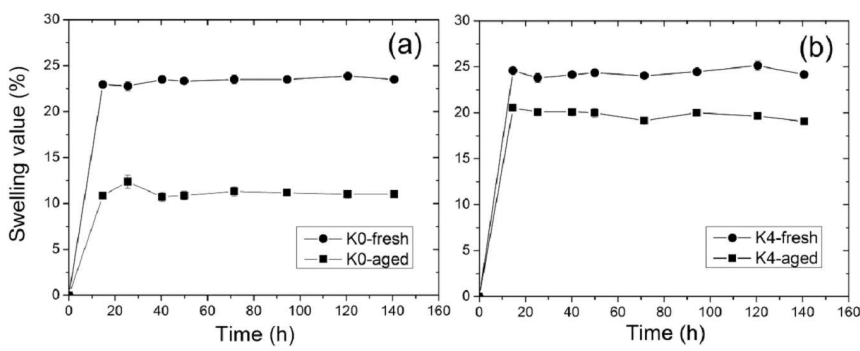

Fig. 3. Swelling value versus time curves for (a) K0fresh and K0-aged and (b) K4-fresh and K4-aged polymers in $\mathrm{EtOH}$ at room temperature. The samples are marked as shown in Fig. 1. The error bars are within the size of the symbol.

TABLE II

Bulk density of the polymeric sample $\left(\rho_{p}\right)$, molecular weight between two crosslink points $\left(M_{c}\right)$ and comparative analysis of crosslinking density or swellability for the investigated polymers. The samples are marked as shown in Fig. 1.

\begin{tabular}{c|c|c|c|c}
\hline \hline Sample & $\rho_{p}\left[\mathrm{~g} / \mathrm{cm}^{3}\right]$ & $M_{c}$ & Crossl. & Swell. \\
\hline K0-fresh & $1.1778 \pm 0.0021$ & 92.47 & - & + \\
\hline K0-aged & $1.1814 \pm 0.0012$ & 44.0 & ++ & -- \\
\hline K4-fresh & $1.2015 \pm 0.007$ & 99.22 & -- & ++ \\
\hline K4-aged & $1.2170 \pm 0.003$ & 76.52 & + & -
\end{tabular}

It is supposed that the network properties obtained by PALS and swelling experiments could be very helpful to understand better the bio-functionality of the constructed biosensor based on the ureasil-chalcogenide glass composite [1]. In this respect, to get more information, a comparative analysis of sensitivity of bioelectrodes constructed using the fresh and aged ureasil composites and PALS and swelling results for these samples is required. Such research is currently in progress.

\section{Conclusion}

Network properties of ureasil-based polymer matrixes suitable for construction of amperometric biosensors have been probed by PALS in the temperature range of 15 $350 \mathrm{~K}$ and swelling experiments. $T_{g}$ and $\alpha_{f v}$ values for 
the investigated polymers have been determined and differences in network behavior for the aged samples and the effect of $\mathrm{As}_{2} \mathrm{~S}_{3}$ particles on the free volume of ureasil network have been observed. The double $T_{g}$ values in the aged ureasil and $\mathrm{As}_{2} \mathrm{~S}_{3}+$ ureasil composites have been detected, while their nature remains not understood yet. Swelling experiments using EtOH have proved that the structure of the aged sample network had less swelling ability for the pure ureasil as well as composite, the most probably due to the change of the basic ureasil network with ageing. A comparative analysis of sensitivity of bioelectrodes constructed using the fresh and aged ureasil composites and PALS and swelling results for these samples is still required to understand better a correlation between network properties of polymer matrix and biofunctionality of the constructed biosensor based on the polymer matrix.

\section{Acknowledgments}

This work was financially supported by the Ministry of Education and Science of Ukraine (project \#0116U004737) (to T.K., O.S., Y.K., and M.G.), by the Slovak Grant Agency VEGA (project \#2/0157/17) (to OŠ) and APVV (project \#16-0369) (to O.S., K.C., H.S., and I.M.), by the National Science Fund of the Bulgarian Ministry of Education (project \#FNI-DN09/12-2016) (to T.K., T.P., V.B., and V.I.). T.K. also acknowledges the SAIA (Slovak Academic Information Agency) for scholarship in the IPSAS within the National Scholarship Programme of the Slovak Republic.

\section{References}

[1] T. Kavetskyy, O. Smutok, M. Gonchar, O. Demkiv, H. Klepach, Y. Kukhazh, O. Šauša, T. Petkova, V. Boev, V. Ilcheva, P. Petkov, A.L. Stepanov, J. Appl. Polym. Sci. 134, 45278 (2017).

[2] R.A. Sá Ferreira, L.D. Carlos, R.R. Gonçalves, S.J.L. Ribeiro, V. de Zea Bermudez, Chem. Mater. 13, 2991 (2001).

[3] V. de Zea Bermudez, L. Alcácer, J.L. Acosta, E. Morales, Solid State Ion. 116, 197 (1999).

[4] E. Stathatos, P. Lianos, U.L. Stangar, B. Orel, P. Judeinstein, Langmuir 16, 8672 (2000).

[5] T. Kavetskyy, O. Šauša, J. Krištiak, T. Petkova, P. Petkov, V. Boev, N. Lyadov, A. Stepanov, Mater. Sci. Forum 733, 171 (2013).

[6] T. Kavetskyy, N. Lyadov, V. Valeev, V. Tsmots, T. Petkova, V. Boev, P. Petkov, A.L. Stepanov, Phys. Status Solidi C 9, 2444 (2012).

[7] V. Boev, A. Soloviev, C.J.R. Silva, M.J.M. Gomes, Solid State Sci. 8, 50 (2006).

[8] V. Boev, J. Pérez-Juste, I. Pastoriza-Santos, C.J.R. Silva, M.J.M. Gomes, L.M. Liz-Marzán, Langmuir 20, 10268 (2004).

[9] Y.C. Jean, Microchem. J. 42, 72 (1990).

[10] P.J. Flory, J. Rehner, Jr., J. Chem. Phys. 12, 412 (1944).

[11] P.J. Flory, J. Chem. Phys. 18, 108 (1950). 